\title{
A Survey of the Application of Information Communication Technology in Education
}

\author{
Seyed Ahmad Hashemy, Daryoosh Hayati, and Zainab Hashemy
}

\begin{abstract}
Heavy competition, lack of supplies and unpredictable fluctuations have made education in the global sphere really difficult, so to confront the new situation, education has to conform and in most cases reform and use more advanced technologies. This essay discusses some new trends in both education and educational management and evaluates them in case of their usages with a descriptiveanalytical approach. Moreover it is discussed how such new technologies are to be applied as well as the changes that must be done to pave the way for changing information communications technology $($ ICT) to public culture. Following these methods will lead to effectiveness of education systems, equal educational opportunities for students in all levels globally.
\end{abstract}

Index Terms - Communication, evaluation, input and output.

\section{INTRODUCTION}

Globalization is what towards which our world is approaching and to be in line with the necessities of globalization, new trends in educational management must correspond too. In fact as the electronic media as internet and the use of cyber space in education are the inseparable elements of education in the global atmosphere today, special attention must be paid on how to use the ICT (Information Communication Technology) to meet the demands of the era. As the world is developing fast, the educational management systems and procedures must conform and adapt too; otherwise, they lack efficiency and are doomed to failure in the long term. Information and communication technology has become a crucial part of the modern world. Now most of the countries emphasize learning and applying the information and communication technology as the core of their educational systems. So it is important to view the ICT in a systematic approach and try to evaluate the advantages of it so as to propose more efficient ideas to improve the field that would consequently lead to better results in practice. The main idea this essay is concerned which is considering the potentials of ICT and suggesting the required conditions to facilitate the application of ICT in education, moreover it is tried to evaluate quality based on a systematic approach too.

Manuscript received January 1, 2012; revised February 22, 2012.

Seyed Ahmad Hashemy is with the Department of Teacher Education, Lamerd Branch, Islamic Azad University, Lamerd, Iran (e-mail: hashemy.ahmad@yahoo.com).

Daryoosh Hayati is with the Department of English, Lamerd Branch, Islamic Azad University, Lamerd, Iran (e-mail: dhhayati1354@gmail.com, dhayati@iaulamerd.ac.ir).

Zainab Hashemy is with the Department of Educational management, Shiraz Branch, Islamic Azad University, Shiraz, Iran.

\section{DISCUSSION}

Systematic thinking could be defined as the process of considering the correlation between or among events and having a holistic view towards organizational elements and "considering an organization as a unique complex concerning the cooperation between or among different components to achieve the desired goals" [1]. To achieve this aim one of the first things to be carefully viewed upon in how to manage the existing technology, systems and available equipment.

\section{Management Technology OF InPUT AND OUtPut OF SYSTEMS}

This type of management includes the application of different methods; hardware, software and processing operations like calculating, control, decision-making, evaluation and filtering to achieve a desired or a specified aim. Information and Communication are defined by the Norwegian Agency as follows: "Information consists of experiences, knowledge and proved propositions to achieve practical results in researches. Communication is the existence of bilateral relations between all objective and nonobjective organizations, units and the constructive factors as well as the people belonging to a society" [2]. According to the above mentioned definitions, information and communication technology means: management of the productions of a network as well as processing, contribution and optimum consumption of information in order to improve the efficiency of systems.

To be more specific, "information and communication technology is a combination of three categories including information, computers and communication technologies" [3], based on which a computer unit is considered as the hardware and provider of necessary tools and facilities for information and communication technology and data is considered as the raw material required for operating systems. Thus to be of practical use, telecommunication is an important unit which serves as a connector among the units, the outcome of which is information which is used in different areas of human expertise, one of which is education. In fact it must be remembered that the ICT is not totally new, rather it has been used in some unsystematic ways ever since the invention if the internet.

\section{HISTORY OF INFORMATION AND COMMUNICATION TECHNOLOGY}

The invention of internet and the widespread use of computers facilitated the possibility of connecting the computers to each other as a result of which a sudden 
change appeared in the communication technology world. The history of internet dates back to the late 1970's in which, the American defense department started an advanced research project to connect several big computers all over the America. New technologies which included communication tools and, computers, internet, software and so on were called information and communication technology and because of its ability in interacting, processing, and storing information with high speed it has miraculously changed human life ever since. One of the effects of this change can be observed in education in 1980s when the internet educational environments. In late 1980s schools were able to connect this technology to other communication technology networks and in 1990's information and communication technology became an inseparable part of educational systems, a trend which is frequently often updated with the new innovations in the field.

\section{THE IMPORTANCE AND ADVANTAGE OF INFORMATION AND COMMUNICATION TECHNOLOGY}

Nowadays there is a special attention to the students' activity in the education systems. Teachers usually try to transfer the required information and skills to their students and provide them with more opportunities in learning. Being provided with the opportunity of selecting and extracting the content of information, new discoveries are brought about in the students. This trend is supported by different scientific theories as the new cultural theory proposed by Seif [4] which emphasizes the importance of student in learning through the ICT. According to some research, "those learners who think independently and emphasize on the process of learning are more successful and stable in their school results compared with the learners that relate their success or failure in education to the teachers or faith or external factors" [5]. Yet e-learning theories emphasize on process-center, self leading and self examining of learners which can be put to practice. As Soaker states:

Application of multimedia technologies in activities increases incredibly, the capacity of storing information increases unimaginably Efficiency increases transforming information is done very fast without considering the dimensions of time and place, market traffic decreases because we don't need to go there and Decision-making goes toward rationality. [6]

In spite of the e-learning theories emphasizing the selfleading function of the learners, attention must be paid to the fact that the function of teachers cannot be ignored. In fact the students' success and their knowledge of the process of learning through the ICT must be led by teachers familiar with its application. As education is a mutual process concerning both students and teachers, the functions and how-to of each must be defined if the process is meant to lead to success.

Teachers' preparation is the major factor for the students' orientation with the potentials of the information and communication technology. Thus to have successful results, some flaws from the teachers' side must be taken into account. "The majority of problems that teachers are faced with in this regard are lack of sufficient training and lack of practical knowledge in the field, while sufficient knowledge of teachers about the potentials and applications of ICT is necessary if fundamental changes are meant" [7]. The teachers must have the ability to teach students the methods of gaining knowledge, ordering, credit making and organization. Teachers must change student knowledge from a short- term intended one to lifelong learning. So teachers' training before the application of ICT in education as well as on job training are indeed necessary conditions to be met. During these two teacher training programs, teachers must be basically changed according to the challenges in the recent century and the curriculum must be prepared based on the information and communication technology to make ICT more efficient in education.

The teachers function would undergo so changes. They are guides and consultants. The teachers teach students the methods of gaining knowledge, ordering, credit making and organization. Some of the functions or skills teachers are expected to have in order to lead to success are, but not limited to the:

1) Creating new skills

2) Making connection between teacher's skills

3) Learning skills

4) Lifelong training of students

5) Orientating students with the application and the potentials if the ICT.

6) The application of a coherent learning system. [8]

In addition to teachers, the students are to be familiarized with the process as they form the second part of this mutual process. Students are the raw materials of all educational systems. They are trained with the efforts, plans and continuous cares of teachers as well as educational experts, moreover as they are the products and a key factor in determining the acridity of the education system in which they are learning, due attention must be paid to them. In this regard according to Alison and Harris [9]: the Assembly of Curriculum Assessment (ACA) has listed the required skills for education the students of 21 century some of the most important ones are as "knowledge of information technology, creative thinking, and the ability of doing group work," [9].

In fact information technology is the key to achieve the above mentioned skills; because the information and communication technology leaves the responsibility of learning to the learners the students have more responsibility about their learning than before.

\section{EQUIPMENT'S, SOURCES AND THE INFORMATION AND COMMUNICATION TECHNOLOGY}

The educational environment in which the information and communication technology is to be practiced needs some special resources and facilities. Facilitates include the basic foundations such as wiring, electricity, computer, libraries, internet access, ventilation, place, rooms and so on. So in this case special attention must be paid to the following necessities: "the more equipped classes and the more software access available, the better tools for making the educational material and creating new and flexible 
multimedia for learning"[10]. Some other applicable resources with the ICT include:

Text: (one of the most used tools in web and for presenting educational contents) documents: (Charts for example excel Software, textbook and essays in PDF format, educational slide for instance Power point programs) picture and voice: (using high speed current picture and voice) email messenger and chat (when some of the class members are synchronously online they can exchange information in this way, yet in some countries like Korea the students daily class activities are emailed to their parents) and other technologies like shared application programs, video conference, simulation and data stations are all examples of useful usages of ICT in education.

\section{ENVIRONMENT AND INFORMATION AND COMMUNICATION TECHNOLOGY}

The method of cooperation between students and teachers and the method of controlling the schools for learning and receiving information and communication technology is a crucial part of learning philosophy, in other words, the corporation of society includes parents, families, foundations, industrial, governmental institutes, social organizations, regional, professional and so on. Moreover one mustn't ignore the effect of international environment. And another important point to be considered is that gaining and building up information and communication technology culture in society affects the culture and atmosphere of the school.

\section{A. Output and ICT}

Capabilities, content, and skills are three different elementary areas of knowledge required for ICT, each of which represents a different dimension that means any action that needs information technology necessarily needs the application of one of the earlier mentioned areas of knowledge. Learning content and the skills of information technology and creating related thought capability without systematic view is impossible. If we look at a problem with a systematic view we understand that in information and communication technology with combining content and capability skills with each other and making the efficient understanding from information technology, the students and citizens are enabled to use the information technology for their personal problem solving and information technology knowledge uses itself in new areas. This combination is a basic element of the students learning in long-term which finally leads to a creation of knowledge and the creative students and its main result is stopping brain drain.

\section{B. Feedback and ICT}

Many educational systems regulate and adapt themselves in such a way that is able "to produce a special output" [11]. The function of ICT in evaluation has enabled teachers to report the students' knowledge and ability to apply it to their education. The students are responsible for their evaluations to edit their own learning styles. Evaluation for students and teachers has a special harmony and a general view of the students is represented in the curriculum. The students "maintain their and their background on the network and edit their preferable curriculum and policy in school. Evaluation of the students and a staffs shows how successful the management of school has been" [12].

\section{MANAGEMENT AND INFORMATION AND COMMUNICATION TECHNOLOGY}

Management technology is an input, process and output of a system. This management includes using methods; hardware, software and processing- means such operations like calculating, control, decision-making, evaluation and filtering. If we pay attention to the Simeon Herbert quotation that management is decision-making we will understand the important role of information and communication technology management because the decision-making is a process that information has important role in it. It means in decision-making we should have the necessary information in order to combine and make a decision. Information technology helps the organization manager to choose necessary information from produced information for its decision then process and use it. Research shows that 'managers' ability to use communication technology to achieve effective management is crucial" [4]. Moreover, "achieving a desired level of practical skills and familiarity with new technologies is essential for managers and is of optimum importance in managers' decision-making" [6]. According to Soaker the communication information technology improves decision-making in managers in the following dimensions:

- Programming is better and more comprehensively done.

- Decision-making time is minimized.

- Managers' errors in organizational information Processing Network reduces.

- Rational decision-making.

\section{CONCLUSION}

A systematic attention to the information and communication technology is clearly recognized as an important and inseparable part of all educational systems, to do so it is required to set a general role as an strategic, corporation and harmony between organizations and ministries, private sectors' contributions, training experts, financial support and expansion of telecommunication networks that finally leads to equal educational opportunity in all levels, education quality, efficiency and the effectiveness of educational system, prevention of brain drain and training job making people.

Moreover, learning management system is for assessment of learners in education and such duties like unit election, registration, gathering information in learner education progress, examination and evaluation system is done by the ICT.

Another useful aspect of the use of ICT is in learning content management system. This system does the management of content and the curriculum which is going to be transferred to learner. And by this system we can 
modify the program and learner can request the desired content that is presented in systems.

So, in order to achieve the above goals attention must be paid to the following suggestions:

1) More efforts and corporation between organization and different ministries is a must

2) Codification of policy and general rules of information and communication technology and modification of rules.

3) Changing the structure of education from a centralized one to a decentralized one.

4) Encouragement and participation of private sector in the establishment and providing the basic requirements to start using information and communication technology in education.

5) Training of managers, teachers, guides and educational groups in relation with content, skills and application of information and communication technology must be efficiently done.

6) Widespread use of scientific sources especially those researches that have been done on information and communication technology and relevant approaches in education are necessary.

7) Preparing security for students in internet networks.

8) Professional efficiency of teachers with expansion of information and communication technology is crucial.

9) Using capability of internet in learning and teaching processes

10) Preparing security for students in internet networks.
11) Establishing virtual schools.

12) Improving the parents' knowledge about the application of ICT in education.

13) Establishing smart schools.

\section{REFERENCES}

[1] Kh. Ebily and H. Movafaghi, A Window to New Management concepts, Tehran: Shiveh Publications. 2004, ch.5, pp.34-36.

[2] Norwegian Agency for Development Cooperation, Information and Communication, 2002. Ch.6, p.98.

[3] M. R. Sepehri, The Role of IT in Human Resource Development and Job Productivity, Tehran: Bahman, 2002. Ch.7,pp.65-67.

[4] A. A. Seif, "Educational Psychology," in Payam-e- Noor Publications, 1995. Ch. 2,pp.346-8.

[5] J. Rotter, "Internal Versus External Control of Reinforcement," in American Psychologist 45(4), 1989, Ch. 3, p.56.

[6] M. R. Soaker, "Educational Modifications and Modernization: with Emphasis on an Analogous Study of Iran and Japan Education," in Roozegar Publication, 2004.ch. 4, pp.59.

[7] N. A. Ghoorchian, Information Technology and Communications in Education, Tehran: Andishe Farashenalrhty publications. 2006, Ch. 6, p.58.

[8] R. S. Abadi, A New Approach Towards Organization, Tehran: Andishe Publications, 2003. ch.5, pp.67-68.

[9] K. Alison and S. Harris, Innovative Classroom: National Implications for schools: Practices using ICT in England Research Foundation for Education, 2002, ch.5, p.45.

[10] Dotton, W. H. Digital Academy the New Media and Institutions of Higher Education and learning. Routledge. 2002, ch.2, pp.87.

[11] A. Alagheband, Theoretical and Instructional Management Principles, Tehran: Raven Publication. 2003, Ch. 4, pp. 45-48.

[12] L. Mahajams, "Information Communication Technology in Distance Education in Iindia," in weekly journal of university news vol.40, pp.45-50, April 2002. 